VNU Journal of Science: Legal Studies

Journal homepage: https://js.vnu.edu.vn/LS

Original Article

\title{
Compensation Liability for Damages Caused by Self-driving Cars in the Tort Law of German and Japan
}

\author{
Nguyen Thi Phuong Cham* \\ VNU School of Law, 144 Xuan Thuy, Cau Giay, Hanoi, Vietnam
}

Received 30 September 2020

Revised 06 December 2020; Accepted 23 December 2020

\begin{abstract}
At the request of society, self-driving cars is entering the practical stage for the purpose of solving a lot of social problems, stimulating the development economy. However, to put Full Automated Driving system into practical use, we must deal with many, various legal concerns. Automatic Driving Technology will reduce the number of transportation accident, but never make it disappear. So in term of responsibility for accident, international law and national law of all countries in the world have identified and found the solutions to reform the law on the issue of self-driving cars. The study of the laws of countries with developed industrial science as Japan and German about "Compensation liability for damages caused by self-driving cars in the tort law" is particularly important for Vietnam.
\end{abstract}

Keywords: Self-driving cars, Compensation liability for damages, tort law of German and Japan.

\footnotetext{
${ }^{*}$ Corresponding author.

E-mail address: chamnguyen1706@gmail

https://doi.org/10.25073/2588-1167/vnuls.4325
} 


\title{
Bồi thường thiệt hại do ô tô tự lái gây ra trong pháp luật Đức và Nhật Bản
}

\author{
Nguyễn Thị Phương Châm * \\ Khoa Luật, Đại học Quốc gia Hà Nội, 144 Xuân Thủy, Cầu Giấy, Hà Nội, Việt Nam \\ Nhận ngày 30 tháng 9 năm 2020 \\ Chỉnh sửa ngày 06 tháng 12 năm 2020; Chấp nhận đăng ngày 23 tháng 12 năm 2020
}

\begin{abstract}
Tóm tắt: Trước yêu cầu của xã hội, ô tô tự lái đang bước vào giai đoạn hiện thực hoá với mục đích giải quyết những tồn đọng trong xã hội, kích thích nền kinh tế phát triển. Tuy nhiên, cùng với ứng dụng ô tô tự lái, chúng ta phải đối mặt với nhiều vấn đề pháp lý đa dạng. Ô tô tự lái sẽ giảm thiểu tai nạn giao thông nhưng không đồng nghĩa với việc tai nạn giao thông sẽ hoàn toàn biến mất. Do vậy, về trách nhiệm bồi thường thiệt hại $(\mathrm{BTTH})$ do sự cố ô tô tự lái gây ra là vấn đề mà pháp luật quốc tế, pháp luật quốc gia của tất cả các nước trên thế giới đã nhận thấy cần thiết phải nhận dạng những tồn tại của pháp luật hiện hành và tìm kiếm giải pháp cho tương lai đối với hệ thống pháp luật về bồi thường thiệt hại. Việc nghiên cứu pháp luật của các nước có nền khoa học công nghiệp phát triển như Nhật Bản và Đức về Trách nhiệm bồi thường thiệt hại do ô tô tự lái gây ra có ý nghĩa đặc biệt quan trọng đối với Việt Nam.
\end{abstract}

Tư khóa: Ô tô tự lái, trách nhiệm bồi thường thiệt hại, bồi thường thiệt hại ngoài hợp đồng trong pháp luật Đức và Nhật Bản.

\section{1. Đặt vấn đề}

Sự vận hành của ô tô thông qua người lái xe thực hiện các thao tác như gia tốc, điều khiển, đạp thắng, do vậy ô tô tự lái đó là sự vận hành của ô tô, cùng với người điều khiển có sự hỗ trợ của hệ thống trong việc xử lý một trong số các thao tác trên, cho đến mức không cần đến thao tác của người lái xe có thể là một phần hoặc hoàn toàn, hệ thống có thể thực hiện sự vận hành này được gọi là hệ thống tự lái [1].

Ô tô truyền thống, người lái xe khi vận hành ô tô: i) phải thu thập, xử lý thông tin để nhận biết; ii) Nắm bắt được thuộc tính của vật thể trên đường để phán đoán (vật cản đường, hay người đi bộ, xe đi ngược chiều,...) và nhận thức được các tình trạng phức tạp khác trên đường; iii) Thực hiện phán đoán dựa trên những nhận thức trên. Nhưng trong cuộc cách mạng

\footnotetext{
*Tác giả liên hệ.

Địa chi email: chamnguyen1706@gmail

https://doi.org/10.25073/2588-1167/vnuls.4313
}

công nghệ 4.0 thông qua sự ra đời của trí tuệ nhận tạo (Artificial Intelligence: $\mathrm{AI}$ ) và mạng kết nối vạn vật (Internet of Things: IoT), khoa học kỹ thuật phát triển như camera, radar, sensor, ngày nay con người tiến đến thực hiện hoá hệ thống giao thông cao độ và khả năng thực hiện kỹ thuật liên quan đến ô tô tự lái trên đường thì đang tiến gần đến mức cao độ.

Với tư cách là định nghĩa mang tính quốc tế "Hệ thống ô tô tự lái" được quy cách hoá và quyết định đưa ra vào năm 2016 bởi Hiệp hội các nhà kỹ thuật ô tô. Theo đó, ô tô tự lái được đưa ra định nghĩa với 5 mức độ theo bảng dưới đây ${ }^{1}$.

\footnotetext{
$\overline{1}$ Tham khảo từ: SAE International Releases Updated Visual Chart for Its "Levels of Driving Automation" Standard for Self-Driving Vehicles https://www.sae.org/news/press-room/2018/12/saeinternational-releases-updated-visual-chart-for-its-"levelsof-driving-automation"-standard-for-self-driving-vehicles (Truy cập ngày 8/4/2019).
} 


\begin{tabular}{|c|c|c|c|}
\hline $\begin{array}{l}\text { Mức độ } \\
\text { của SAE }\end{array}$ & $\begin{array}{c}\text { Mức độ tự động } \\
\text { hoá }\end{array}$ & Tổng quan & $\begin{array}{c}\text { Chủ thể giám sát, xử lý để việc } \\
\text { vận hành xe an toàn }\end{array}$ \\
\hline 0 & $\begin{array}{l}\text { Hoàn toàn không tự } \\
\text { động hoá trong vận } \\
\text { hành }\end{array}$ & $\begin{array}{l}\text { Người lái xe thực hiện toàn bộ nhiệm } \\
\text { vụ vận hành xe. }\end{array}$ & Người lái xe \\
\hline 1 & Hỗ trợ người lái xe & $\begin{array}{l}\text { Hệ thống thực hiện hỗ trợ nhiệm vụ vận } \\
\text { hành xe liên quan đến một trong các thao } \\
\text { thác như tiến-lùi hoặc trái-phải. }\end{array}$ & Người lái xe \\
\hline 2 & $\begin{array}{l}\text { Tự lái theo bộ phận } \\
\text { chức năng }\end{array}$ & $\begin{array}{l}\text { Hệ thống thực hiện hỗ trợ nhiệm vụ } \\
\text { vận hành nhưng bao gồm cả hai tiến- } \\
\text { lùi, quay phải-trái mang tính chất thực } \\
\text { hiện thao tác, ngoài bộ phần gia tốc, có } \\
\text { thể tự lái bộ phận thắng phanh,... }\end{array}$ & Người lái xe \\
\hline 3 & $\begin{array}{l}\text { Tự lái kèm theo } \\
\text { điều kiện }\end{array}$ & $\begin{array}{l}\text { Hệ thống tự lái thực hiện nhiệm vụ vận } \\
\text { hành toàn bộ (Nhưng hạn chế trong } \\
\text { một số lĩnh vực, nội dung như thời } \\
\text { gian, trong một số tình huống nhất } \\
\text { định,...). } \\
\text { Trong trường hợp sự vận hành của hệ } \\
\text { thống gặp khó khăn, Người lái xe phải } \\
\text { kịp thời tiếp nhận việc điều khiến xe } \\
\text { khi có yêu cầu can thiệp từ hệ thống. }\end{array}$ & $\begin{array}{l}\text { Hệ thống } \\
\text { (Nhưng trong trường hợp việc } \\
\text { thao tác do hệ thống gặp khó } \\
\text { khăn thì chủ thể có nghĩa vụ } \\
\text { giám sát là người lái xe) }\end{array}$ \\
\hline 4 & Tự lái mức độ cao & $\begin{array}{l}\text { Hệ thống thực hiện nhiệm vụ vận hành } \\
\text { toàn bộ (Có giơoi hạn). } \\
\text { Trong trường hợp thao tác của hệ } \\
\text { thống gặp khó khăn cũng không kỷ } \\
\text { vọng sự đối phó của người lái. }\end{array}$ & Hệ thống \\
\hline 5 & Tự lái hoàn toàn & $\begin{array}{l}\text { Hệ thống thực hiện nhiệm vụ vận hành } \\
\text { toàn bộ (ko có giới hạn). } \\
\text { Kỳ vọng không có người lái, tất cả } \\
\text { những người trên xe đều được xem là } \\
\text { hành khách. }\end{array}$ & Hệ thống \\
\hline
\end{tabular}

Xe ô tô tự lái với việc phân các mức độ như trình bày ở nội dung trên, khi đạt đến mức độ 4,5 pháp luật về Bồi thường thiệt hại sẽ phải gặp các vấn đề sau khi đặt trong pháp luật hiện hành.

Thứ nhất: Vấn đề xác định chủ thể chịu trách nhiệm BTTH thiệt hại trong trường hợp ô tô tự lái gặp sự cố gây thiệt hại².

Thứ hai: Mối quan hệ pháp lý giữa các chủ thể chịu trách nhiệm BTTH. Đặc biệt là mối quan hệ trong vấn đề phân chia trách nhiệm

\footnotetext{
2 Tự thân khái niệm về người điều khiển phương tiện sẽ gặp phải rất nhiều vấn đề, trong trường hợp khuyết tật của hệ thống tự lái dẫn tới sự cố thì liệu việc chủ sở hữu, người điều khiển phương tiện chịu trách nhiệm như luật hiện hành có phù hợp hay không?
}

giữa người điều khiển phương tiện và nhà sản xuất [2].

Thứ ba: Mối quan hệ giữa chủ thể chịu trách nhiệm $\mathrm{BTTH}$ và cơ chế bảo hiểm ${ }^{3}$

\section{Bồi thường thiệt hại đối với ô tô tự lái trong pháp luật Nhật Bản}

\subsection{Pháp luật hiện hành về bồi thường thiệt hại ngoài hơp đồng đối với ô tô tụ lái}

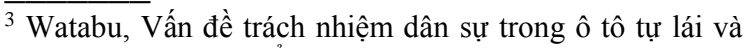
khuynh hướng bảo hiểm (12/2016):

https://www.jkri.or.jp/PDF/2016/Rep148watabe.pdf\#searc $\mathrm{h}=\% 27$, (truy cập ngày $8 / 4 / 2019$.
} 
Về trách nhiệm bồi thường thiệt hại ngoài hợp đồng, hiện tại pháp luật tồn tại các quy chế pháp lý sau: Bộ luật dân sự Nhật Bản, Luật bồi thường thiệt hại do ô tô gây ra, Luật trách nhiệm sản phẩm và Luật bồi thường nhà nước.

Quy định tại Điều 709 Bộ luật dân sự Nhật Bản (BLDSNB), được xem như quy định chung về trách nhiệm BTTHNHĐ điều chỉnh các mối quan hệ chung nhất với mục đích bù đắp thiệt hại do hành vi bất hợp pháp gây ra xâm hại đến sức khoẻ, tính mạng, tài sản của người khác. Điều kiện cấu thành trách nhiệm BTTH trong phần chung yêu cầu điều kiện như: Tồn tại hành vi vi phạm, tồn tại yếu tố lỗi, có thiệt hại và mối quan hệ nhân quả giữa hành vi vi phạm và thiệt hại.

Với điều kiện cấu thành trách nhiệm BTTH như trên, Nhật Bản thấy rằng đối với trường hợp ô tô gây tai nạn, việc quy trách nhiệm chứng minh tồn tại yếu tố lỗi của người gây hại là quá khắt khe đối với người bị hại, và hậu quả kéo theo người bị hại không thể được bù đắp thiệt hại do mình gây ra [3].

Với lý do trên, Luật bồi thường thiệt hại do ô tô gây ra với tư cách là luật chuyên ngành của Bộ luật Dân sự (BLDS) về lĩnh vực BTTH được xây dựng. Song song với Luật BTTH do ô tô gây ra, hệ thống pháp luật BTTH của Nhật Bản còn có Luật Trách nhiệm sản phẩm, Luật Bồi thường nhà nước với tư cách đặc định hoá các chủ thể khác nhau có nghĩa vụ BTTH trong mối quan hệ pháp lý với người bị hại do ô tô gây ra.

2.1.1. Luật Bồi thường thiệt hại do ô tô gây ra

Theo Điều 3 Luật BTTH do ô tô gây ra loại bỏ điều kiện lỗi trong cấu thành trách nhiệm BTTH tại BLDS như vậy người bị hại không có nghĩa vụ chứng minh tồn tại yếu tố lỗi cố ý hoặc vô ý của người gây hại. Tuy nhiên, Luật BTTH do ô tô gây ra trong pháp luật Nhật Bản có những đặc thù như sau: Thứ nhất, chỉ bảo vệ người bị hại trong trường hợp bị xâm hại tính mạng, thân thể mà không bảo vệ đối tượng quyền lợi bị xâm hại là tài sản; Thứ hai, nguyên tắc trách nhiệm không lỗi được áp dụng nhưng kèm theo đó là cơ chế miễn trừ trách nhiệm dựa trên nguyên lý rủi ro phát triển. Cụ thể Điều 3 Luật BTTH do ô tô gây ra quy định hai vấn đề pháp lý quan trọng: Điều kiện cấu thành trách nhiệm BTTH và cơ chế miễn trừ được quy định như sau:

Người liên quan đến vận hành ô tô vì bản thân mình có trách nhiệm bồi thường thiệt hại khi xâm hại tính mạng, thân thể của người khác do vận hành ô tô gây ra. Tuy nhiên, không áp dụng trách nhiệm nếu chứng minh được bản thân người này và người điều khiển phương tiện không lơ là chú ý trong khi vận hành xe ô tô, lỗi hoàn toàn do người thứ ba không phải người bị hại và người điều khiển, không tồn tại khuyết tật trên cấu tạo xe.

Xoay quanh điều khoản này, hiện nay các luật gia đang tranh luận các vấn đề như sau khi bàn luận về việc đối với sự ra đời và phát triển của ô tô tự lái việc áp dụng điều khoản này còn có phù hợp hay không? Nếu không phù hợp thì cơ chế sửa đổi pháp luật được tiến hành $\mathrm{ra} \mathrm{sao}^{4}$ ?

Về khái niệm chủ thể có trách nhiệm bồi thường trong Luật BTTH do ô tô gây ra, chủ thể chịu trách nhiệm trong Luật BTTH do ô tô gây ra là "Người cung cấp việc sử dụng vận hành ô tô vì bản thân mình". Và như vậy chủ thể chịu trách nhiệm BTTH được giải thích theo nghĩa rất rộng không chỉ người điều khiển, vận hành phương tiện mà bao gồm cả phạm vi người nhận được những lợi ích từ việc vận hành xe đó. Theo án lệ Nhật Bản, chủ thể chịu trách nhiệm BTTH là chủ thể có quyền chi phối việc điều khiển xe hoặc chủ thể nhận được lợi ích thông qua việc điều khiển xe [4] Qua đó, việc công nhận phạm vi chủ thể chịu trách nhiệm như trên được đánh giá có ý nghĩa quan trọng trong việc thực hiện chức năng chế định trách nhiệm bồi thường thiệt hại ngoài hợp đồng (BTTHNHĐ) đó là bù đắp thiệt hại và phân tán thiệt hại.

Tuy nhiên, đối với sự phát triển khoa học công nghệ, đặc biệt sự ra đời của ô tô tự lái, các nhà làm luật nhận thấy rằng hầu hết các sự cố tai nạn ô tô từ trước tới nay đều có nguyên nhân từ lỗi của người vận hành hoặc người liên quan đến vận hành, mục đích của ô tô tự lái sẽ giảm thiểu các vấn đề trên, nhưng không thể nói ô tô

${ }^{4}$ https://www.jkri.or.jp/PDF/2016/Rep148watabe.pdf\#sear $\mathrm{ch}=\% 27$, (truy cập ngày $8 / 4 / 2019$. 
tự lái hoàn toàn sẽ không phát sinh sự cố liên quan đến tai nạn, khả năng gia tăng sự cố ngoài lỗi của người điều khiển, người liên quan sẽ phát sinh. Do vậy, đối với ô tô tự lái sẽ đặt ra câu hỏi như sau: Thứ nhất, với sự ra đời của ô tô tự lái thì việc duy trì khái niệm về chủ thể chịu trách nhiệm BTTH hiện hành có phù hợp hay không? Có nghĩa là chủ sở hữu của ô tô tự lái là chủ thể gánh chịu trách nhiệm BTTH với tư cách là người liên quan đến vận hành (người có lợi ích trong việc vận hành) liệu rằng có phù hợp không? Nhà sản xuất ô tô có trách nhiệm ra sao đối với những thiệt hại do sự cố của hệ thống tự lái? Trường hợp thông tin, dữ liệu số hoá bị hack dẫn tới sự cố thì trách nhiệm sẽ do ai gánh vác? Đối với sự cố gây thiệt hại trong quá trình sử dụng hệ thống tự lái có hay không cần thiết là đối tượng được Luật BTTH do ô tô gây ra hiện hành bảo vệ? [5].

\subsubsection{Luật trách nhiệm sản phẩm}

Trường hợp do khuyết tật của hàng hóa, sản phẩm gây ra thiệt hại về tính mạng, thân thể, tài sản của chủ thể pháp luật dân sự thì nhà sản xuất, chế tạo phải gánh chịu trách nhiệm BTTH, Luật Trách nhiệm sản phẩm được xem là Luật chuyên ngành của BLDS về trách nhiệm BTTHNHĐ. Theo Điều 3 Luật trách nhiệm sản phẩm Nhật Bản, chỉ cần sản phẩm có khuyết tật không cần điều kiện lỗi vẫn cấu thành trách nhiệm BTTHNHĐ. Tuy nhiên, theo Điều 4, người gây hại được miê̂n trừ trách nhiệm trong trường hợp chứng minh được khoa học hiện tại không thể phát hiện ra khuyết tất hoặc đã chỉ dẫn thiết kế về khuyết tật và cảnh báo. Căn cứ nền tảng hình thành trách nhiệm này đó là trách nhiệm nghiêm ngặt, trách nhiệm bù đắp tổn thất, trách nhiệm niềm tin [3].

Tuy nhiên, trong thời đại kỹ thuật số việc áp dụng Luật trách nhiệm sản phẩm có phải là giải pháp hữu hiệu bù đắp thiệt hại hay không đang trở thành vấn đề bàn luận. Việc xe ô tô tự lái ngày nay hệ thống tự lái sử dụng phần mềm, kết nổi internet dự liệu nhiều vướng mắc. Ví dụ, về chủ thể chịu trách nhiệm là nhà sản xuất ô tô, hay là nhà sản xuất bộ phận. Tiếp đến, hàng hoá, sản phẩm (vật-đối tượng) có bao gồm các chương trình liên quan đến hệ thống tự lái hay không? Về điều kiện liên quan đến "Khuyết tật" trường hợp chương trình không có tác động mang tính vật lý thì khuyết tật được hiểu đến phạm vi nào? Tiếp đến nghĩa vụ chứng minh quan hệ nhân quả giữa khuyết tật và thiệt hại theo pháp luật hiện hành người bị hại phải có nghĩa vụ chứng minh, tuy nhiên đối với trường hợp ô tô tự lái thì việc chứng minh này rất khó. Nói cách khác, Luật trách nhiệm sản phẩm hiện nay không được xem là luật đặc hoá trong lĩnh vực ô tô mà chỉ là luật điều chỉnh chung đối với tất cả hàng hoá, sản phẩm, do vậy quy chế pháp lý trong luật này hoàn hoàn được thiết kế vào thời kỳ chưa tồn tại hiện thực hoá xã hội có sự xuất hiện của ô tô tự lái. Kéo theo đó không tránh được những giới hạn nhất định trong việc áp dụng luật với mục đích giải quyết các vấn đề mang tính pháp lý một cách thoả đáng và hợp lý [3].

\subsubsection{Luật bồi thường nhà nước}

Luật bồi thường nhà nước quy định trách nhiệm bồi thường thiệt hại của nhà nước, tổ chức công, trong trường hợp phát sinh thiệt hại cho người bị hại do khuyết tật của tài sản mang tính công như đường xá, cầu, cống,... hoặc do lỗi trong quản lý, vận hành thì nhà nước hoặc tổ chức công phải có trách nhiệm bồi thường thiệt hại. Theo Điều 2 Luật Bồi thường nhà nước Nhật Bản trách nhiệm BTTH này là trách nhiệm không dựa trên lỗi. Về vấn đề cấu thành trách nhiệm của người quản lý cầu cống, đường xá trong trường hợp sự cố giao thông có nguyên nhân từ khuyết tật của cơ sở hạ tầng công cộng được cho rằng rất khó nói tại thời điểm hiện tại khi nó phụ thuộc vào hình thái cơ sở hạ tầng đáp ứng đối với ô tô tự lái, luật áp dụng,... và kỳ vọng của xã hội về tính an toàn cần thiết của cơ sở hạ tầng đối với ô tô tự lái,... Đặc biệt khi ô tô tự lái đạt đến trình độ cấp độ cao hoặc hoàn toàn tự lái, thì rõ ràng việc hoạt động, vận hành của ô tô phụ thuộc rất nhiều vào cơ cở hạ tầng, do vậy có thể khẳng định việc luận bàn về trách nhiệm BTTH của chủ thể này là một trong những vấn đề pháp luật BTTH ngoài hợp đồng phải đối diện [5].

Do vậy, ứng với các mức độ tự lái của ô tô, Nhật Bản đưa ra nhận định rằng: Pháp luật hiện hành đã đáp ứng được việc giải quyết các vấn đề pháp lý trong phạm vi sự cố ô tô tự lái ở mức 
độ thứ 2 gây ra. Đối với ô tô tự lái từ mức độ 3 việc áp dụng pháp luật hiện hành cho thấy tồn tại nhiều vấn đề. Chính vì vậy, khoa học phát triển cụ thể việc thực hiện hoá ô tô tự lái hoàn toàn (mức độ 4,5$)$ cho thấy nền tảng pháp lý hiện hành không thể đáp ứng. Do vậy, Nhật Bản đang thúc đầy nhanh tiến trình nghiên cứu để đưa ra giải pháp xây dựng, sửa đổi pháp luật liên quan sao cho đáp ứng được nhu cầu phát triển của xã hội [5].

\subsection{Vấn đề tồn tại và giải pháp liên quan đến} cái cách pháp luật trong lĩnh vực bồi thuờng thiệt hại ngoài hơp đồng do ô tô tụ lái gây ra

2.2.1. Chủ thể BTTH trong Luật BTTH do ô tô gây ra có phù hợp hay không?

Đối với ô tô tự lái đặc biệt tự lái đạt tới mức độ 4,5 thì việc chủ sở hữu, doanh nghiệp vận chuyển bằng ô tô gánh chịu trách nhiệm $\mathrm{BTTH}$ được pháp luật Nhật Bản giải thích vẫn phù hợp với Luật BTTH do ô tô gây ra bởi theo luật hiện hành thông qua giải thích tư pháp thì chủ thể được hiểu đó là chủ thể chi phối việc vận hành (điều khiển), hoặc chủ thể nhận lợi ích từ việc vận hành ô tô. Do vậy đối với ô tô tự lái cho dù chủ thể không chi phối việc vận hành xe nhưng có lợi ích từ việc vận hành.

Tuy nhiên vấn đề cần giải quyết đó là, mối quan hệ giữa các chủ thể chịu trách nhiệm BTTH (phân bổ rủi ro) cần được minh bạch rõ trong thực trạng ô tô tự lái. Cụ thể, trong trường hợp ô tô tự lái gặp sự cố do nguyên nhân khiếm khuyết của hệ thống (và đây là nguyên nhân chủ yếu được dự liệu đối với ô tô tự lái trình độ cao) thì liệu rằng chủ sở hữu, doanh nghiệp vận tải bằng phương tiện ô tô,... có thể chấp nhận việc phải gánh chịu trách nhiệm BTTH không? Trách nhiệm của nhà sản xuất trong trường hợp này đến đâu? Là những vấn đề phải được nghiên cứu rõ [6].

Đối với vấn đề này, cụ thể trong trường hợp khiếm khuyết của hệ thống là nguyên nhân phát sinh trách nhiệm BTTH thì chủ thể gánh chịu trách nhiệm là ai? Dưới đây là 3 phương án cụ thể: [6].

i) Duy trì trách nhiệm của chủ thể trong Luật BTTH do ô tô gây ra, xây dựng mô hình để hiệu quả hoá thông qua công ty bảo hiểm yêu cầu trách nhiệm BTTH đối với doanh nghiệp sản xuất.

ii) Duy trì trách nhiệm của chủ thể trong Luật BTTH do ô tô gây ra, xây dựng quy chế yêu cầu gánh vác một phần nhất định ngay từ đầu thông qua số tiền bảo hiểm đối với doanh nghiệp sản xuất.

iii) Duy trì trách nhiệm của chủ thể trong Luật BTTH do ô tô gây ra, về sự cố do hệ thống tự lái gây ra cần nghiên cứu sao cho doanh nghiệp sản xuất phải gánh chịu trách nhiệm không dựa trên lỗi thông qua việc xây dựng khái niệm trách nhiệm của người cung ứng hệ thống tự lái.

Đối với 3 phương án trên hiện nay phương án (2), (3) nhận được nhiều ý kiến không đồng tình bởi những lý do sau:

Về phương án (2): Thứ nhất, việc tính toán để đưa ra một công thức tỷ lệ số tiền bảo hiểm mà nhà sản xuất, nhà nhập khẩu phải chi trả thông qua tỉ lệ chi phối của hệ thống tự lái trong vấn đề vận hành ô tô là điều không dễ dàng. Thứ hai, xây dựng quy chế truy thu bảo hiểm đảm bảo độ chính xác từ nhà sản xuất, nhập khẩu rất phức tạp. Thứ ba, mức độ tự lái của ô tô khác nhau do vậy chế độ bảo hiểm đối với nhà sản xuất sẽ có khả năng tạo ra sự thiếu đồng nhất trong cơ chế bảo hiểm xe ô tô hiện tại [6].

Về phương án (3): Thứ nhất, đối với nhà sản xuất, sau khi bán ô tô tự lái khả năng liên tục phải chịu trách nhiệm không dựa trên lỗi vô thời hạn thì phải chăng trách nhiệm như vậy là quá lớn. Thứ hai, có quan điểm không thể phủ nhận đó là trách nhiệm của người cung cấp hệ thống được xem là trách nhiệm sản phẩm dựa trên Luật Trách nhiệm sản phẩm. Thứ ba, trong trường hợp tồn tại song song trách nhiệm của hai chủ thể đó là người vận hành xe và nhà cung cấp hệ thống tự lái thì việc xác định tỉ lệ gánh chịu trách nhiệm giữa chủ thể trong Luật BTTH do ô tô gây ra và chủ thể người cung cấp hệ thống sẽ rất khó khăn [6].

Và đặc biệt một lý do khác phản đối hai phương án trên, đó là dưới góc nhìn pháp luật so sánh, Mỹ, Đức, Anh không quốc gia nào áp dụng phương án, cũng như đưa ra đề án cải 
cách theo khuynh hướng nhà sản xuất sẽ phải gánh chịu một phần trách nhiệm nhất định được quy định trước.

2.2.2. Trường hợp sự cố do hacking (cắp dữ liệu điện toán mà không được phép) gây ra, thì vấn đề chủ thể chịu trách nhiệm sẽ được giải quyết ra sao?

Theo Luật Bồi thường thiệt hại do ô tô gây ra thì trong trường hợp sự cố tai nạn xảy ra đối với xe bị mất cắp mà hoàn toàn không có sự liên quan đến người quản lý xe thì được giải thích người quản lý) người liên quan đến vận hành xe (chủ thể chịu trách nhiệm BTTH) hoàn toàn mất sự chi phối việc vận hành xe cũng như những lợi ích nhận được từ sự vận hành [7]. Do vậy không trở thành chủ thể chịu trách nhiệm theo Luật hiện hành, do không phát sinh trách nhiệm BTTH đối với chủ thể này nên người bị hại sẽ không được bù đắp thiệt hại thông qua công ty bảo hiểm trách nhiệm (Bởi chủ thể được bảo hiểm - một bên trong hợp đồng là người quản lý xe ô tô). Chính vì vậy, để hiệu quả hoá chức năng bù đắp thiệt hại, trong trường hợp này theo khoản 1 Điều 72 Luật BTTH do ô tô gây ra quy định Tổ chức nghiệp vụ đảm bảo bù đắp thiệt hại của chính phủ (trực thuộc Bộ Giao thông đường bộ Quốc gia) sẽ bù đắp thiệt hại cho người bị hại và sau đó Bộ giao thông đường bộ quốc gia có quyền yêu cầu người gây hại bồi hoàn.

Với quy chế hiện hành được cho rằng: Hoàn toàn đáp ứng với thực trạng xe ô tô tự lái gây tai nạn khi bị hacking. Tuy nhiên trong trường hợp việc hacking được thực hiện do nguyên nhân tồn tại khuyết tật của hệ thống thì sau đó chính phủ hoàn toàn có quyền yêu cầu nhà sản xuất bồi hoàn chi phí BTTH [6].

\section{Pháp luật của Cộng hoà liên bang Đức}

Ở Đức, một trong những lý do chiến lược ứng dụng ô tô tự lái từ chạy thí điểm trên đường cao tốc tới thực hiện hoá trong đời sống chạy trên đường nói chung đó là giảm thiểu các vụ tại nạn giao thông do ô tô gây ra (phần lớn cho rằng nguyên nhân từ lỗi của con người, lỗi hành động hoặc không hành động). Nhưng với thực trạng như vậy không có nghĩa là sẽ tránh được hoàn toàn các vụ va chạm, sự cố liên quan tới an toàn giao thông, ngược lại những rủi ro sự cố với đặc thù, tính chất mới sẽ ra tăng thay vì những tai nạn trước đây với những đặc thù tính chất khác là điều được dự báo. Do vậy với thực trạng xã hội có sự thay đổi như vậy thì việc nghiên cứu trách nhiệm dân sự nói chung, trách nhiệm BTTHNHĐ nói riêng trong bối cảnh xã hội mới khi có sự xuất hiện của ô tô tự lái là điều không thể thiếu ${ }^{5}$.

\subsection{Chủ thể chịu trách nhiệm bồi thường thiệt hại}

Ở Đức khi vận hành ô tô, trường hợp gây thiệt hại đối với tính mạng, thân thể, sức khoẻ hay tài sản của người khác, người quản lý, người điều khiển phương tiện phải chịu trách nhiệm BTTH dựa trên Điều 7, Điều 18, Luật giao thông đường bộ và Điều 823 Bộ luật dân sự Đức (BGB).

\subsubsection{Trách nhiệm của người quản lý}

Về khái niệm người quản lý thì theo án lệ Đức là người sử dụng vì lợi ích của bản thân, và người có quyền cơ bản để sử dụng xe. Trách nhiệm của người quản lý theo khoản 1 Điều 7 Luật Giao thông đường bộ, là trách nhiệm nghiêm ngặt không liên quan đến điều kiện có hay không lỗi. Đây là điểm khác biệt lớn so với trách nhiệm BTTH dựa trên Điều 823 BGB khi điều kiện lỗi là yếu tố không thể thiếu cấu thành trách nhiệm BTTH. Liên quan đến điều kiện miễn trừ trách nhiệm, theo khoản 2 Điều 7 Luật Giao thông đường bộ quy định ngoài trường hợp bất khả kháng, ngay cả khi sự cố do khuyết tật về tình trạng của $x e$, lắp đặt mang tính kỹ thuật thì người quản lý vẫn phải gánh chịu trách nhiệm BTTH. Tuy nhiên có một điểm đáng lưu ý, Theo Điều 12 Luật Giao thông đường bộ sửa đổi 2017 (Thông qua 16/6/2017, được công bố ngày 20/6/2017 và có hiệu lực thi hành ngày 21/6/2017), mức BTTH tối đa khi ô tô gây ra đã được nâng lên gấp đôi so với tai nạn thông

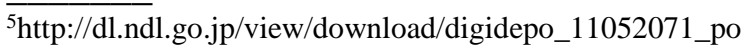
_02750004.pdf?content $\mathrm{No}=1$, truy cập ngày $9 / 3 / 2018$.
} 
thường, sự cố liên quan đến tính mạng, thân thể là 10 triệu Euro, và sự cố liên quan đến tài sản 2 triệu Euro ${ }^{6}$. Trách nhiệm của người quản lý khi vượt quá mức tối đa này, người bị hại hoàn toàn có quyền yêu cầu trách nhiệm BTTH dựa trên lỗi được quy định tại Điều 823 BGB. Người quản lý phải có nghĩa vụ tham gia bảo hiểm trách nhiệm vì bản thân mình, chủ sở hữu, người điề̀ khiển (Theo Điều 1 Luật về Bảo hiểm trách nhiệm của người quản lý ô tô). Như vậy, trong trường hợp người thứ 3 khi bị thiệt hại có quyền yêu cầu người quản lý hoặc người điều khiển phương tiện BTTH thì những thiệt hại sẽ được bù đắp thông qua bảo hiểm trách nhiệm. Theo Điểm 1 khoản 1 Điều 115 Luật Hợp đồng bảo hiểm, người bị hại được công nhận trực tiếp quyền yêu cầu bên bảo hiểm bồi thường thiệt hại.

3.1.2. Trách nhiệm của người điều khiển phương tiện

Đoạn 1 khoản 1 Điều 18 quy định Trách nhiệm BTTH của người điều khiển phương tiện và đoạn 2 có quy định: "Trường hợp người điều khiển chứng minh được mình không có lỗi sẽ không phải chịu trách nhiệm BTTH”. Như vậy theo Luật Giao thông đường bộ, trách nhiệm của người điều khiển không phải trách nhiệm nghiêm ngặt mà là trách nhiệm chuyển giao nghĩa vụ chứng minh lỗi. Ví dụ, người điều khiển chứng minh được tuy vận hành xe đúng nhưng do thiết bị, lắp đặt dẫn tới sự cố thì được xem như không cấu thành yếu tố lỗi của người điều khiển. Thêm vào đó, giống như trường hợp người quản lý, trách nhiệm BTTH theo Luật giao thông đường bộ sẽ bị giới hạn mức tối đa, vượt quá mức đó, người bị hại yêu cầu BTTH phải dựa trên quy định chung về BTTHNHĐ tại BLDS và như vậy yêu cầu người bị hại phải có nghĩa vụ chứng minh lỗi của người điều khiển.

\subsection{Trách nhiệm bồi thương thiệt hại của nhà sản xuất}

$\overline{{ }^{6} \mathrm{http}: / / d l . n d l}$.go.jp/view/download/digidepo_11052071_po _02750004.pdf?contentNo=1, truy cập ngày 9/3/2018.
Nhà sản xuất, chế tạo ô tô theo đoạn 1 khoản 1, Điều 1, Luật Trách nhiệm sản phẩm Đức trong trường hợp gây thiệt hại về tính mạng, thân thể, sức khoé, tài sản của ngừoi khác do khuyết tật của sản phẩm phải có trách nhiệm BTTH đối với người khác. Trách nhiệm BTTH của nhà sản xuất theo Luật trách nhiệm sản phẩm là trách nhiệm nghiêm ngặt [8]. Theo khoản 1 , Điều 3 , Luật này việc công nhận khuyết tật trong trường hợp sản phẩm thiếu tính an toàn thông thường, khuyết tật được chia làm: Khuyết tật trong thiết kế; Khuyết tật trong chế tạo; Khuyết tật trên chỉ dẫn, cảnh báo. Mức tối đa đối với trách nhiệm BTTH trong Luật trách nhiệm sản phẩm về con người là 85 triệu Euro (khoản 1 Điều 10).

3.2.1. Trách nhiệm bồi thường thiệt hại đối với giai đoạn ô tô tự lái

i) Trách nhiệm của người quản lý

Đối với trách nhiệm của người quản lý, Điều 12 Luật Giao thông đường bộ sửa đồi 2017 quy định về giới hạn mức bồi thường được giải thích là phù hợp và điều chỉnh bao quát toàn bộ các mức ô tô tự lái, tuy nhiên cũng đặt ra câu hỏi có hay không cần thiết tăng cường điều kiện mới khi quy trách nhiệm của người quản lý ứng với trường hợp ô tô tự lái, đặc biệt ô tô tự lái khi đạt đến trình độ tự lái hoàn toàn. Trong trường hợp thao tác của hệ thống tự lái hỗ trợ mắc lỗi thì theo khoản 1 , Điều 7 vẫn công nhận trách nhiệm của người quản lý với nền tảng rủi ro vận hành và được giải thích cho dù có sự thay đổi căn bản trong ô tô tự lái nhưng dưới góc độ pháp lý thì được giải thích không có sự thay đổi trong vấn đề trách nhiệm BTTH [8]. Tuy nhiên, vẫn tồn tại nhưng vấn đề mà pháp luật Đức thấy rằng trong thời gian tới phải tiếp tục nghiên cứu và được giải quyết thông qua việc sửa đổi, xây dựng pháp luật. Đó là trường hợp sự cố giao thông xảy ra thông qua việc có sự can thiệp của hacker, thì liệu rằng trong trường hợp này có xem xét với tư cách bất khả kháng để miễn trừ trách nhiệm $\mathrm{BTTH}$ cho người quản lý hay không?

3.2.2. Trách nhiệm của người điều khiển

Trách nhiệm của người điều khiển theo Điều 18 Luật giao thông đường bộ được cho là 
đối với trường hợp ô tô tự lái một phần thì luật hiện hành hoàn toàn có thể áp dụng mà không có sự mâu thuẫn. Tuy nhiên, trình độ ô tô tự lái ở mức độ cao độ hoặc hoàn toàn khi mà không cần thiết có sự giám sát hệ thống của người vận hành thì liệu rằng trách nhiệm $\mathrm{BTTH}$ dựa trên suy đoán lỗi có còn phù hợp hay không? Việc sử dụng hệ thống tự lái và người vận hành hoàn toàn giao việc vận hành cho hệ thống với phương thức chính xác thì trong trường hợp này người điều khiển có hay không khả năng miễn trách nhiệm. Bên cạnh đó, đối với trường hợp ô tô tự lái việc không công nhận lỗi (không tồn tại nghĩa vụ) của người điều khiển sẽ dẫn tới hậu quả mức tổn thât vượt quá giới hạn được quy định tại Điều 12 Luật giao thông đường bộ sửa đổi, hầu như không có khả năng bù đắp thông qua quy định tại phần chung BLDS (khoản 1 Điều 823), do vậy có hay không cần thiết sửa đổi giới hạn mức bồi thường được quy định tại Điều 12 đối với trách nhiệm BTTH của người điều khiển. Thêm vào đó trong trường hợp sự cố phát sinh gây thiệt hại cho người khác khi hệ thống tự lái ngừng khẩn cấp nhưng người điều khiển trong tình trạng mất nhận thức ko phải do lỗi thì được miê̂n trách nhiệm BTTH theo đoạn 2, khoản 1, Điều 18.

Tại Đức, người chế tạo hệ thống tự động điều khiển, thông qua chương trình phần mềm điều khiển, tạo ra những ảnh hưởng rất lớn trên thực tiễn ứng dụng đối với việc lắp đặt kỹ thuật căn bản liên quan đến vận hành, cái này cho dù là hệ thống được mã số định hình hoá dưới những tiêu chuẩn được xác định nhưng vì nó tiến hành các quyết định liên quan đến vận hành của ô tô nên người chế tạo hệ thống được giải thích là người điều khiển ô tô, do vậy có thuyết cho rằng người chế tạo phần mềm cần thiết chịu trách nhiệm của người điều khiển theo luật hiện hành ${ }^{7}$.

\subsubsection{Trách nhiệm của nhà sản xuất}

Đối với trường hợp ô tô tự lái một phần, người điều khiển khi thấy cần thiết phải vận hành ô tô thay cho hệ thống, tuy nhiên đối với

\footnotetext{
${ }^{7}$ Theo trích dẫn 28 từ Goto Gen, “Thực trạng của Đức về vấn đề Ô tô tự lái và trách nhiệm dân sự” Tạp chí Jurist No.1501 (1/2017), tr.48
}

loại sản phẩm này nếu nhà sản xuất không có chỉ dẫn cảnh báo cụ thể về thời điểm cần thiết giám sát hệ thống, thời điểm thích hợp chuyển giao việc vận hành từ tự động sang người điều khiển,... thì nhà sản xuất phải gánh chịu trách nhiệm trong trường hợp này.

Đối với thực trạng xã hội ô tô tự lái, cần thiết phải nghiên cứu rõ ràng và cụ thể về nội dung nghĩa vụ giám sát vật chế tạo đối với người sản xuất không quá khắt khe, cho dù không phủ nhận nghĩa vụ này cần thiết tồn tại ở một mức độ nào đó. Về mối quan hệ giữa người điều khiển và nhà sản xuất ở mức độ 2,3 , thì được giải thích như sau: Trong trường hợp vấn đề liên quan đến hệ thống tự lái phức tạp với một khoảng thời gian khó có thể nhận định và điều chỉnh kịp thời thì nên hiểu là người điều khiển không có lỗi. Và việc hệ thống không thể tránh được những rủi ro đó được xem là khuyết tật tồn tại trong quá trình thiểt kế và như vậy nhà sản xuất có khả năng phải chịu trách nhiệm [8].

Ngược lại, đối với hệ thống tự lái hoàn toàn, nhà sản xuất phải thiết kế sao cho phục hồi hệ thống tự lái trong tất cả trường hợp, người điều khiển thậm trí được xem là không tồn tại, và nếu có cũng hoàn toàn không có nghĩa vụ liên quan đến việc giám sát hệ thống cũng như chú ý đến việc vận hành có hay không sự cố. Do vậy, trong quá trình tự lái có sự cố và gây thiệt hại cho người khác thì các học giả của Đức giải thích áp dụng trách nhiệm của nhà sản xuất trong mọi trường hợp trừ khi chứng minh được nguyên nhân của sự cố do sự vi phạm giao thông của người thứ $\mathrm{ba}^{8}$.

Vậy, trong pháp luật của Đức thông qua việc giải thích pháp luật hiện hành thấy rõ đối với thực trạng ô tô tự lái, đang có khuynh hướng và được cho rằng dần trở thành nguyên tắc: Chủ thể chịu trách nhiệm là nhà sản xuất. Nhưng có điểm cần lưu ý, đối với trường hợp ô tô tự lái một phần, cũng có khả năng nguyên nhân của sự cố tai nạn gây thiệt hại tồn tại song song lỗi của người điều khiển và khuyết tật trong hệ thống thiết kế của nhà sản xuất, hoặc

\footnotetext{
${ }^{8}$ Goto Gen, "Thực trạng của Đức về vấn đề Ô tô tự lái và trách nhiệm dân sự” Tạp chí Jurist No.1501 (1/2017)
} 
sự cố va chạm giữa hai xe tự lại hoàn toàn, do vậy được dự liệu việc đoán định liên quan đến nghĩa vụ lập chứng nguyên nhân sự cố và lỗi là một trong những vấn đề cực kỳ phức tạp. Vì vậy pháp luật Đức đặt ra những vấn đề như thu thập, bảo quản, giữ gìn dữ liệu trước và sau sự cố [8].

\subsection{Mối quan hệ giữa ô tô tư lái và bảo hiểm trách nhiệm bồi thường thiệt hại}

Hiệp hội bảo hiểm Đức đã chính thức đưa ra ý kiến về bảo hiểm trách nhiệm đối với ô tô tự lái vào ngày 25 tháng 5 năm 2016: "Bảo hiểm trách nhiệm BTTH do ô tô gây ra, đảm bảo trong cả trường hợp ô tô tự lái. Cho dù trong trường hợp sự cố do hệ thống tự lái, bảo hiểm vẫn duy trì chức năng bù đắp thiệt hại cho người bị hại’'[9].

Tuy nhiên sự cố phát sinh trong trường hợp xe tự lái được chia làm 3 nguyên nhân [10]: i) Trường hợp do lỗi của người điều khiển phương tiện; ii) Trường hợp do khuyết tật của sản phẩm; iii) Trường hợp do những khiếm khuyết khác gây ra.

Trường hợp i) Doanh nghiệp bảo hiểm về nguyên tắc không yêu cầu người điều khiển hoàn trả phí bảo hiểm đã bồi thường cho người bị hại trừ khi người điều khiển vi phạm nghĩa vụ liên quan đến việc dùng các chất kích thích trong quá trình vận hành.

Trường hợp ii) Doanh nghiệp bảo hiểm có quyền truy đòi khoản tiền BTTH cho người bị hại đối với nhà sản xuất nếu chứng minh được tồn tại khuyết tật trong thiết kế, lắp ráp những bộ phận có khuyết tật, lỗi trong quá trình sửa chữa của công trường sửa chữa, khuyết tật trong việc update phần mềm.

Trường hợp iii) Doanh nghiệp bảo hiểm có quyền yêu cầu hacker-người thay đổi hệ thống phần mềm trong quá trình ô tô tự lái hoạt động, bồi thường chi phí doanh nghiệp đã bù đắp thiệt hại cho người bị hại.

\section{Kết luận}

Nghiên cứu chỉ dừng lại ở góc nhìn giới thiệu hệ thống pháp luật hiện hành của Nhật Bản và Đức đối với vấn đề xã hội mới (xã hội nhân tạo) trong trường hợp cụ thể là bồi thường thiệt hại do ô tô tự lái gây ra. Song đã cho thấy, cho dù đối với các hiện tượng xã hội mới việc thích ứng của hệ thống pháp luật luôn và vấn đề cấp thiết được đặt ra. Song với nền tảng pháp luật cốt lõi được xây dựng hoàn thiện vẫn có khả năng hoàn toàn đáp ứng được trước sự biến đổi của thời đại.

\section{Tài liệu tham khảo}

[1] Fujiwara Shizuo, "Những tồn tại xoay quanh ô tô tự lái và khái quát những vấn đề pháp lý” Tạp chí Luật Hiroba Quyển 70 Số 5 (5/2017).

[2] Makiko Okamoto, Katsuo Nakahira, "Sự thay đổi trong quan niệm xã hội cùng với sự hỗ trợ cao độ của xe tự lái và Tố tụng dân sự trong tai nạn giao thông - Điều chỉnh quan niệm xã hội xoay quanh vấn đề phân bổ trách nhiệm của người điều khiển phương tiện và nhà sản xuất - " Tạp chí Human Interface Vol.19, No.3 (2017).

[3] Nakagawa Yuka, "Sự thay đổi nội dung trách nhiệm mang tính luật trong sự cố tai nạn giao thông sau ứng dụng ô tô tự lái Sự khác nhau giữa trách nhiệm hình sự và trách nhiệm dân sự” Tạp chí Chukyo Lawyer Số 25 (2016).

[4] Án lệ của Toà tối cao ngày 18 tháng 9 năm 1969, Tuyển tập án dân sự Quyển 23 Số 9 Tr. 1699

[5] Koji Toshima, Thực trạng và vấn đề tồn tại trong chế độ pháp lý trước hiện thực ô tô tự lái NBL No.1074 (5/2016)

[6] Bản báo cáo của Cục ô tô Bộ giao thông đường bộ Nhật Bản, "Nghiên cứu về trách nhiệm bồi thường thiệt hại ngoài hợp đồng do ô tô gây ra", 3/2018.

[7] Tuyển tập án lệ dân sự số 135, tr. 641 .

[8] ${ }^{9} \mathrm{Cụ} \mathrm{thể} \mathrm{được} \mathrm{sửa} \mathrm{đổi} \mathrm{tại} \mathrm{Điều} \mathrm{32,} \mathrm{Điều} \mathrm{63a,} \mathrm{Điều}$ 63b Luật Giao thông đường bộ lần thứ 8. p.47, 53. http://dl.ndl.go.jp/view/download/digidepo_1105207 1_po_02750004.pdf?contentNo=1.

[9] http://www.gdv.de/2016/05/so-sind-unfaelle-durchautomatisierte-fahrsysteme-versichert/.

[10] Goto Gen, "Thực trạng của Đức về vấn đề Ô tô tự lái và trách nhiệm dân sự” Tạp chí Jurist No.1501 (1/2017). 